\title{
Cross-species incompatibility between a DNA satellite and a chromatin protein poisons germline genome integrity
}

Cara L. Brand and Mia T. Levine*

Department of Biology and Epigenetics Institute, University of Pennsylvania, Philadelphia, PA

Running title: adaptive evolution to preserve genome integrity

Keywords: DNA satellite, coevolution, chromatin, maternal haploid, 359

*Corresponding Author:

Dr. Mia Levine, University of Pennsylvania, 433 S. University Avenue, Philadelphia, PA 19104. p: 215-573-9709 e: m.levine@sas.upenn.edu. 


\section{ABSTRACT}

Satellite DNA spans megabases of eukaryotic genome sequence [1]. These vast stretches of tandem DNA repeats undergo high rates of sequence turnover, resulting in radically different satellite DNA landscapes between closely related species [2-4]. Such extreme evolutionary plasticity suggests that satellite DNA accumulates mutations with no functional consequence. Paradoxically, satellite-rich genomic regions support essential, conserved nuclear processes, including chromosome segregation, dosage compensation, and nuclear structure [5-10]. A leading resolution to this paradox is that deleterious alterations to satellite DNA trigger adaptive evolution of chromatin proteins to preserve these essential functions [11]. Here we experimentally test this model of coevolution between chromatin proteins and DNA satellites by conducting an evolution-guided manipulation of both protein and satellite. We focused on an adaptively evolving, ovary-enriched chromatin protein, called Maternal Haploid (MH) from Drosophila. MH co-localizes with an $11 \mathrm{Mb} 359$-bp satellite array present in Drosophila melanogaster but absent in its sister species, $D$. simulans [12]. Using CRISPR/Cas9-mediated transgenesis, we swapped the $D$. simulans version of $\mathrm{MH}$ into $D$. melanogaster. We discovered that $D$. melanogaster females encoding only the $D$. simulans $m h$ (" $m h[s i m f$ ") do not phenocopy the $m h$ null mutation. Instead, $\mathrm{MH}[\mathrm{sim}]$ is toxic to $D$. melanogaster ovaries-we observed elevated ovarian cell death, reduced ovary size, and subfertility in $\mathrm{mh}$ [sim] females. Using both cell biological and genetic approaches, we demonstrate that $\mathrm{MH}[\mathrm{sim}]$ poisons oogenesis through a DNA damage pathway. Remarkably, deleting the $D$. melanogaster-specific 359 satellite array from $\mathrm{mh}[\mathrm{sim}]$ females completely restores female germline genome integrity and fertility. This genetic rescue offers experimental evidence that rapid evolution resulted in a cross-species incompatibility between the 359 satellite and $\mathrm{MH}$. These data suggest that coevolution between ostensibly inert repetitive DNA and essential chromatin proteins preserves germline genome integrity. 


\section{RESULTS AND DISCUSSION}

Satellite-enriched genomic regions evolve rapidly and yet support strictly conserved nuclear functions [2-10]. A classic resolution to this paradox is that DNA satellite-associated proteins evolve adaptively to mitigate deleterious changes to DNA satellite sequence [11]. Repeated bouts of DNA satellite evolution and host chromatin protein adaptation result in exquisitely coevolved satellites and satellite-associated chromatin proteins. This model of coevolution predicts pervasive incompatibilities between satellite DNA and chromatin proteins from closely related species: adaptively evolving chromatin proteins from one species should fail to package or process DNA satellites from another [11, 13, 14].

Evidence for this coevolution model has emerged from engineering "evolutionary mismatches" between the chromatin protein(s) of one species and the DNA satellite landscape of a close relative. Under one approach, a diverged chromatin protein is introduced into a closely related species, generating an evolutionary mismatch between the manipulated protein and one or more DNA satellites [14-17]. Consistent with disrupted DNA satellite:chromatin protein coevolution, the naïve chromatin protein typically perturbs a satellite-mediated function, such as chromosome segregation or nuclear organization $[14,16,17]$. In these cases, however, the incompatible DNA satellites are unknown. A second approach crosses sister species to generate evolutionary mismatches between chromatin proteins and DNA satellites. Consistent with disrupted DNA satellite:chromatin protein coevolution, interspecies hybrid inviability has been linked to DNA satellites $[18,19]$. In these cases, however, the incompatible chromatin proteins are unknown. To date, there are no cases of experimental identification of both chromatin protein and satellite putatively engaged in coevolution.

To experimentally probe both sides of the coevolution model, we searched for a rapidly evolving DNA satellite that colocalizes with an adaptively evolving chromatin protein. In Drosophila melanogaster, the 359-bp satellite occurs in an $11 \mathrm{Mb}$ array at the base of the $\mathrm{X}$ chromosome $[20,21]$. Close relatives of $D$. melanogaster, including $D$. simulans and $D$. erecta, lack this satellite array on the $\mathrm{X}$ chromosome [22]. Instead, these close relatives of $D$. melanogaster have shorter arrays of "359-like" sequence dispersed throughout heterochromatin and euchromatin $[3,23,24]$. Such extreme lineage-restriction to $D$. melanogaster makes this DNA repeat an ideal satellite to test the coevolution model. On the protein side, we identified from the literature Maternal Haploid (MH), a protein that colocalizes with the 359 satellite [12]. $\mathrm{MH}$ is ovary-enriched protein and maternally provisioned to the embryo [12, 25]. The name "maternal haploid" comes from a striking phenotype in the embryos of $\mathrm{mh}$ null mothers: paternal chromosomes fail to participate in the first embryonic mitosis. Only $20 \%$ of these embryos develop beyond the first division and with only the haploid complement of maternal chromosomes. Moreover, developing "maternal haploid" embryos from $\mathrm{mh}$ null mothers accumulate fragmented arrays of 359 [12]. $m h$ between $D$. melanogaster and $D$. simulans. To determine if $m h$ evolves adaptively, we conducted a McDonald-Kreitman test [26] using polymorphism within D. melanogaster and 
$D$. simulans and divergence between $D$. melanogaster and $D$. simulans (2.5 million years diverged [27]. This comparison revealed an excess of nonsynonymous fixations, consistent with a history of adaptive evolution (Figure 1A). The dynamic evolution of the 359 satellite and adaptive evolution of a 359-associated protein, $\mathrm{MH}$, raise the possibility that $\mathrm{mh}$ recurrently evolves to preserve a biological function compromised by 359 satellite proliferation.

To test the possibility of MH-359 coevolution, we first conducted an evolution-guided manipulation of $m h$. We predicted that generating an "evolutionary mismatch" between the $D$. simulans $m h$ and the $D$. melanogaster $359 \mathrm{bp} \mathrm{X-linked} \mathrm{array} \mathrm{would} \mathrm{compromise} \mathrm{an} \mathrm{essential}$ nuclear function. To perform this swap, we used CRISPR/Cas9 to integrate into the native $m h$ locus either a 3xFLAG-tagged $D$. melanogaster $m h$ coding sequence (our control fly, " $m h$ [mel]") or a 3xFLAG-tagged $D$. simulans $m h$ coding sequence (our experimental fly, " $m h$ [simf", Figure $1 B$ ). Both the $D$. melanogaster and the $D$. simulans coding sequences were codon-optimized for D. melanogaster. We observed equivalent expression of the two transgenes (Figure S1A). Given that MH is ovary-enriched [12, 25], we first quantified female fertility across our two genotypes. $\mathrm{mh}$ [sim] females produced significantly fewer progeny than the control $\mathrm{mh}$ [mel] females (Figure 1C). Upon dissecting the ovaries from each genotype, we observed significantly smaller mh[sim] ovaries (Figure 1D).

An oogenesis defect was unexpected: previous reports suggest that $m h$ null alone yields no ovary phenotype $[12,25]$. Consistent with these data, we detected no difference in ovary size of $m h$ null mothers compared to heterozygous controls (Figure S1B). To further probe the difference between $\mathrm{mh}[\mathrm{sim}]$ and $\mathrm{mh}$ null females, we assayed the embryos of $\mathrm{mh}[\mathrm{sim}]$ mothers. If $\mathrm{mh}[\mathrm{sim}]$ behaves as loss of function allele in a $D$. melanogaster genetic background, we expect $\mathrm{mh}[\mathrm{sim}]$ mothers to give rise to elevated "maternal haploid" embryos, similar to $\mathrm{mh}$ null mothers. To address this prediction, we crossed $\mathrm{mh}$ [mel] mothers and $\mathrm{mh}$ [sim] mothers to fathers homozygous for an EGFP-tagged centromere protein, CID. Diploid embryos, but not maternal haploid embryos, inherit the paternally-supplied EGFP-cid transgene. We observed no difference in the incidence of EGFP:CID-lacking embryos across $m h$ [mel] and $m h$ [sim] mothers. (Figure S1C). These data, combined with the unexpected oogenesis phenotype, suggest that $\mathrm{mh}[\mathrm{sim}]$ does not behave as a loss-of-function allele. Instead, MH[sim] might be toxic.

To explore the possibility that $\mathrm{MH}[\mathrm{sim}]$ is toxic, we first asked if $\mathrm{MH}[\mathrm{sim}]$ localizes aberrantly in the ovary. We visualized $\mathrm{MH}[\mathrm{mel}]$ and $\mathrm{MH}[\mathrm{sim}]$ by staining ovaries with anti-FLAG. We discovered that while $\mathrm{MH}[\mathrm{mel}]$ localized primarily in the earliest stages of oogenesis (the germarium), $\mathrm{MH}[\mathrm{sim}]$ localized not only in these early stages of oogenesis but also on the "nurse cell" nuclei of later stage egg chambers and weakly on the somatic follicle cell nuclei (Figure 2A, 2B, S2). The aberrant persistence of $\mathrm{MH}$ [sim] during oogenesis, combined with compromised $\mathrm{mh}[\mathrm{sim}]$ ovary development, raised the possibility that $\mathrm{MH}$ mislocalization alone might be toxic. To test this hypothesis, we used the UAS-GAL4 system to overexpress MH[mel] in the female germline (driver nos-Gal4-VP16, Figure 2C). In ovaries overexpressing MH[mel], we indeed observed elevated levels and aberrant persistence of the protein in later stage egg chambers. Nevertheless, these females gave rise to abundant progeny (Figure $2 \mathrm{C}$ ), suggesting that mislocalization alone cannot explain the compromised ovary development of $\mathrm{mh}$ [sim] 
119

120

121

122

123

124

125

126

127

128

129

130

131

132

133

134

135

136

137

138

139

140

141

142

143

144

145

146

147

148

149

150

151

152

153

154

155

156

157

158

159

160

161

162

females. In contrast, overexpression of $\mathrm{MH}[\mathrm{sim}]$ in otherwise wildtype ovaries resulted in female sterility (Figure $2 \mathrm{C}$ ). These data suggest that $\mathrm{MH}[\mathrm{sim}]-$ which functions normally in its native $D$. simulans genome - is toxic to oogenesis in $D$. melanogaster. Indeed, in the ovaries expressing the CRISPR-introduced $\mathrm{mh}[\mathrm{sim}$ ] transgene under the native promoter (Figure 1B), we discovered an excess of hyper-condensed nuclei, consistent with elevated cell death (Figure $2 \mathrm{D}[28,29])$.

A classic trigger of cell death is the accumulation of DNA damage [30]. To visualize DNA damage, we stained $\mathrm{mh}[\mathrm{mel}]$ and $\mathrm{mh}[\mathrm{sim}$ ] ovaries for the double-stranded break marker, $\mathrm{yH} 2 \mathrm{Av}$. We observed elevated DNA damage signaling in $\mathrm{mh}$ [sim] ovaries (Figure 3A). These data suggest that $\mathrm{MH}[\mathrm{sim}]$ triggers DNA damage in the ovary. To address the hypothesis that $\mathrm{MH}[\mathrm{sim}]$ compromises oogenesis through a DNA repair pathway, we combined $\mathrm{mh}$ [sim] with a null mutation in a DNA damage checkpoint gene. The gene, Chk2 (also known as $m n k$ ), normally blocks egg production in the presence of DNA damage [31, 32]. Chk2 ${ }^{-/}$ovaries bypass this checkpoint, allowing a female to make mature but damaged eggs in the presence of elevated DNA damage. We discovered that $C h 2^{-/-}$restores $\mathrm{mh}$ [sim] ovaries to $\mathrm{mh}[\mathrm{mel} /$-like ovary size (Figure 3B). However, the $\mathrm{mh}[\mathrm{sim}] ; \mathrm{Chk}^{-/-}$females are sterile while $\mathrm{mh}[\mathrm{mel}]$; Chk2 ${ }^{-/-}$ females retain fertility (Figure $3 \mathrm{C}$ ). These data suggest that $\mathrm{MH}[\mathrm{sim}]$ compromises oogenesis by triggering DNA damage.

Applying these phenotypic data to the coevolution model, we hypothesized that the expanded $11 \mathrm{Mb}$ array of 359 satellite in $D$. melanogaster triggers DNA damage in the presence of $\mathrm{MH}[\mathrm{sim}]$. Under this model, $\mathrm{MH}$ [sim]-specific residues are incompatible with 359. Removing 359 should restore germline genome integrity and fertility of $\mathrm{mh}$ [sim] females. To directly test this prediction, we took advantage of a fly strain that lacks the $11 \mathrm{Mb}$ array of X-linked 359 satellite [33]. We recombined this 359-deletion, called Zygotic hybrid rescue, or "Zhr," onto both the $\mathrm{mh}[\mathrm{mel}]$ and the $\mathrm{mh}[\mathrm{sim}] \mathrm{X}$ chromosomes (Figure S3A). If $\mathrm{MH}$ [sim]-induced toxicity depends on the presence of the 359 expansion, $\mathrm{mh}[\mathrm{sim}], \mathrm{Zhr}$ females should have minimal DNA damage and recover fertility. Remarkably, the 359-deletion completely restores the DNA damage signal $\mathrm{yH} 2 \mathrm{Av}$ to wildtype (low) levels (Figure 4A). Consistent with restored germline genome integrity of $\mathrm{mh}[\mathrm{sim}$ ] females, we observed no difference in ovary size of $\mathrm{mh}$ [mel] and $\mathrm{mh}$ [sim] females that lack 359 (Figure 4B). Finally, the 359-deletion completely restores $\mathrm{mh}$ [sim] fertility (Figure 4C). These data suggest that 359 mediates $\mathrm{MH}[\mathrm{sim}]$ toxicity to oogenesis, consistent with a history of coevolution between these two fast-evolving components of the Drosophila genome (Figure 4D, 4E).

The molecular events that trigger 359-dependent DNA damage in $\mathrm{mh}$ [sim] ovaries remain to be elucidated. We suspect that $\mathrm{MH}[\mathrm{sim}]$ interferes with a chromatin-mediated pathway required to mitigate 359-induced challenges to the female germline (and possibly other stages of development). The MH human homolog, Spartan, clips DNA-protein crosslinks that accumulate at replication forks using the Spartan-like protease domain [34-36]. Based on this molecular function, we hypothesize that DNA replication challenges at the $11 \mathrm{Mb}$ array of 359 cause the accumulation of chromatin intermediates replete with persistent DNA-protein crosslinks. These crosslinks are normally resolved by other members of the Spartan family, like GCNA [37]. We 
speculate that $\mathrm{MH}[\mathrm{sim}]$ traps these DNA-protein crosslinks, triggering replication fork collapse and DNA damage (Figure S3B). Alternatively, MH[sim] may disrupt the production of 359 transcripts shown previously to recruit essential chromosome segregation factors to the centromere [10].

The deletion of 359 from the $D$. melanogaster $\mathrm{X}$ chromosome renders this genomic region " $D$. simulans-like" [22]. The rescue of germline genome integrity upon combining $\mathrm{mh}[\mathrm{sim}]$ and the $D$. simulans-like 359 deletion implicates 359 proliferation as the antagonizing event that triggered $\mathrm{MH}$ adaptive evolution (Figure 4E). However, we cannot rule out the possibility that a selection pressure distinct from 359 proliferation triggered $\mathrm{MH}$ adaptive evolution. Under this alternative model, the $D$. melanogaster-specific version of $\mathrm{MH}$ evolved first, releasing constraint on 359 copy number. Based on the exceptionally rapid rates of DNA satellite evolution, combined with empirical observations that DNA satellites can behave selfishly by gaining a transmission advantage from one generation to the next [38,39], we favor instead a model under which 359 proliferated first (Figure 4E).

The 359-mediated toxicity to oogenesis highlights the catastrophic functional consequences of DNA satellite evolution. Importantly, 359-mediated toxicity is also apparent in D. melanogaster$D$. simulans hybrid embryos: a distinct, unmapped gene on the $D$. simulans chromosome 2 [4043] interacts deleteriously with 359 to cause embryonic chromosome mis-segregation, genome instability, and lethality [18, 33, 44]. This interspecies hybrid dysfunction in the embryo, together with the $m h[s i m]-359$ toxicity in the ovary reported here, suggests that recurrent bouts of coevolution not only shape essential genome functions within species but also can trigger hybrid incompatibilities between species. Our experimental identification of both satellite and protein engaged in coevolution offers the clearest evidence to date that ostensibly inert DNA repeats trigger adaptive chromatin protein evolution to maintain genome integrity. 


\section{MATERIALS AND METHODS}

\section{Population genetic and molecular evolution analyses}

We conducted population genetic analysis of $m h$ using multiple alleles from both $D$. melanogaster and $D$. simulans. We obtained eight $D$. melanogaster $m h$ alleles (coordinates $X: 15472804-15475400$, dmel r6.4) from lines collected in Lyon, France [45]. We amplified seven $D$. simulans $m h$ alleles from lines collected in Nairobi, Kenya [46]. We prepared genomic DNA and conducted PCR amplification followed by Sanger sequencing using standard protocols. We aligned the sequences in Geneious using the Geneious Alignment algorithm with default settings (Geneious v11.1.5, Biomatters, Auckland, New Zealand) and confirmed alignment quality by eye. We performed a McDonald-Kreitman test [26] with the $D$. melanogaster and D. simulans $m h$ coding sequences.

\section{Fly stock construction and husbandry}

\section{Constructing gene swaps}

We used CRISPR/Cas9 to generate $D$. melanogaster flies that encode a transgenic

$D$. melanogaster allele or a $D$. simulans allele of $m h$, integrated into the native location. We first generated a U6 promoter-driven guide RNA construct by cloning sgRNAs flanking the coding sequence of $m h$ (5': GGATTGGCCCAGGATCAACA, 3': CGTGGAGAGCTTCTGCCGCG) into pBFv-U6.2 and pBFv-U6.2B backbones. We shuttled the 3' sgRNA into pBFv-U6.2 to create a dual sgRNA vector (University of Utah Mutagenesis Core). In parallel, we constructed homology directed repair (HDR) plasmids encoding one kilobase (kb) homology arms 5' and 3' of their respective guide RNAs. Between the homology arms we synthesized a codon-optimized (for $D$. melanogaster) $m h$ coding sequence from either $D$. melanogaster or $D$. simulans (GenScript, Piscataway, NJ). We N-terminally tagged each sequence with 3xFLAG along with a linker sequence (GGTGGTTCATCA). We injected the dual sgRNA vector and a single HDR plasmid into the Cas9-expressing line, yw; nos-Cas9(II-attP40) (BestGene Inc, Chino Hills, CA).

We crossed the single males, injected as embryos, to an FM7 (X-chromosome balancer) female. We screened $F_{1}$ females to identify positive transformants using forward primer 5'-AAGTGTCGCGCTATTTCACC-3' and reverse primer

5'-TCACCGTCATGGTCTTTGTAGTCCAT-3'. We then backcrossed the positive $\mathrm{F}_{1}$ females to FM7 males and self-crossed the balanced $F_{2}$ progeny to generate lines homozygous for either allele. To confirm that the introduced alleles encoded the expected sequence and in the expected location, we amplified the entire region from homozygous flies using primers that anneal outside of the homology arms (5'-AATGGATTTCGGCAAATGAG-3', 5'-GTCGTTGTAGGAGCCCATGT-3') and then sequenced across the entire region. We also designed primers that amplified the native $m h$ locus (5'-GGCCCTGCTCATATCGTATC-3', 5'-AAGAACCTTACTGCGTGCAAC-3') to confirm that our final genotypes were true 
We used the $\Phi C 31$ integrase-mediated transgenesis system to introduce into the same landing site $m h$ from $D$. melanogaster or $D$. simulans downstream of an "upstream activating sequence" or "UAS" [47]. Using the HDR plasmids as a template (see above), we PCR-amplified the 3xFLAG-tagged $m h$ coding sequence (either $D$. melanogaster or $D$. simulans) using Phusion High-Fidelity DNA Polymerase (NEB, Ipswich, MA). We cloned the resulting PCR products into Notl/Xbal sites of the pUASp-attB vector (Drosophila Genomics Resource Center, Bloomington, IN). We confirmed the absence of PCR-introduced mutations in the cloned UAS-mh[mel] and UAS- $m h[s i m]$ alleles by direct Sanger sequencing of the constructs (Table S1). We introduced the constructs into $D$. melanogaster $y w$; PBac $\left[y^{+}\right.$-attP-9A]VK00018 flies, which have an attP transgene landing site at cytological position 75A10 on chromosome 3L, (BestGene Inc, Chino Hills, CA). We next made each transgene homozygous. To overexpress the transgenic alleles, we crossed these stocks to Gal4::VP16-nos (BDSC \#64277), which drives germline expression of transgenes downstream of UAS.

\section{Zhr rescue stocks}

To generate stocks that encode both the $\mathrm{X}$-linked $m h$-transgene and the $\mathrm{X}$-linked 359 satellite deletion ( $Z h r^{1}$, BDSC \#25140), we first generated trans-heterozygote females. We crossed these trans-heterozygote females to FM7 males and used PCR to assay individual recombinant male progeny for the presence of both the $m h$ transgene and Zhr. We detected the $m h$ transgene with forward primer 5'-AAGTGTCGCGCTATTTCACC-3' and reverse primer 5'-TCACCGTCATGGTCTTTGTAGTCCAT-3'. To detect the Zhr mutation (i.e., 359 satellite deletion), we used forward primer 5'-TATTCTTACATCTATGTGACC-3' and reverse primer 5'-GTTTTGAGCAGCTAATTACC-3' [10]. Running this PCR with a 52C annealing temperature for 10 cycles yields a band only in the presence of the $11 \mathrm{Mb} 359$ satellite array. We backcrossed males positive for both the $\mathrm{mh}$ transgene and $\mathrm{Zhr}$ mutation to FM7 females to generate a permanent stock.

We used a +/FM7; +/CyO stock to generate flies encoding both the $m h$ transgene at the native locus (chromosome $X$ ) and the $\mathrm{Chk}^{-1-}(m n k)$ mutation (chromosome 2). The $m n k^{16}$ stock [32] was a gift from N. Phadnis.

\section{Immunoblotting}

To assay protein abundance in the ovary, we dissected 20 ovary pairs in $1 \mathrm{X}$ PBS and ground the material in RIPA buffer (Cell Signaling Technology, Danvers, MA), Protease Inhibitor Cocktail (Roche, Basel, Switzerland), and 2X PMSF (Cell Signaling Technology, Danvers, MA). To promote solubility, we incubated the lysate in Benzonase (Sigma Aldrich, St. Louis, MO) for $1 \mathrm{hr}$ at $4 \mathrm{C}$. We used $20 \mu \mathrm{g}$ of lysate and probed with 1:10,000 anti-FLAG (M2, Sigma Aldrich, St. Louis, MO) or 1:1,000 anti- $\alpha$-tubulin (Developmental Studies Hybridoma Bank, lowa City, IA) and 1:1,000 anti-mouse HRP secondaries (Kindle Biosciences, Greenwich, CT). We exposed 
blots with Kwikquant Western Blot detection kit and imaged with a Kwikquant imager (Kindle

277 Biosciences, Greenwich, CT).

278

279

280

281

282

283

284

285

286

287

288

289

290

291

292

293

294

295

296

297

298

299

300

301

302

303

304

305

306

307

308

309

310

\section{Fertility assays}

\section{Female fertility}

To assay female fertility, we first aged virgin females 3-5 days. For each replicate vial, we crossed four virgin females to four $w^{1118}$ males. We conducted all crosses on molasses food at $24^{\circ} \mathrm{C}$. We flipped the parents onto new food every three days over the course of nine days and counted all progeny that emerged.

\section{Ovary size}

To determine ovary size from the gene swap lines and the mutant line $m h^{1}$ (BDSC \#64277), we dissected ovary pairs in 1X PBS and imaged at 8X magnification with a Leica DFC7000 T camera. We quantified the area of each ovary using the polygon tool in FIJI [48] to define the borders of the tissue. For each ovary pair, we used the Measure tool in FIJI to calculate the area $\left(\mathrm{mm}^{2}\right)$ within these boundaries for each individual ovary.

\section{Immunofluorescence}

We conducted immunofluorescence on ovaries following the protocol described in [49]. We stained ovaries with anti-FLAG (1:3000, M2, Sigma Aldrich, St. Louis, MO) and anti-yH2Av (1:1000, a gift from R. S. Hawley). We mounted ovaries with ProLong Gold Antifade Reagent with DAPI (Thermo Fisher Scientific, Waltham, MA). We imaged slides at $63 x$ magnification on a Leica TCS SP8 Four Channel Spectral Confocal System. For each experiment, we used the same imaging parameters across genotypes.

We conducted immunofluorescence on embryos from $\mathrm{mh}[\mathrm{mel}]$ or $\mathrm{mh}[\mathrm{sim}]$ females crossed to males homozygous for P\{gcid.EGFP.cid\}III.2 ([50], gift from K. McKim). We followed the protocol described in [51] to fix and stain the embryos with anti-GFP (1:1000, Aves Labs, Tigard, OR). We mounted and imaged the embryos as described above.

\section{Analysis of cytological data}

\section{Cell death quantification}

To quantify the incidence of cell death, we mounted fixed whole ovaries with ProLong Gold Antifade Reagent with DAPI (Thermo Fisher Scientific, Waltham, MA) and imaged at 63x magnification on a Leica TCS SP8 Four Channel Spectral Confocal System using the tile scanning and merging feature. We identified the number of ovarioles that contained egg chambers with $>1$ condensed, signal-saturated nurse cell nucleus. We then divided this number 
316 by the total number of ovarioles present in each ovary to determine the fraction of cell death

317 incidence in $\mathrm{mh}[\mathrm{mel}]$ and $\mathrm{mh}[\mathrm{sim}]$ ovaries.

Immunofluorescence quantification

We quantified the average fluorescence of $\mathrm{yH} 2 \mathrm{Av}$ in stage four egg chambers in $\mathrm{mh}[\mathrm{mel}]$ and

$322 \mathrm{mh}[\mathrm{sim}]$ ovaries. First, we outlined a representative stage four egg chamber with the Freehand

$323 \mathrm{ROI}$ tool in FIJI [48]. We calculated the fluorescent signal intensity following the protocol described by the Keith R. Porter Imaging Facility (https://kpif.umbc.edu/image-processingresources/imagej-fiji/, UMBC, Baltimore, MD). We normalized the fluorescent signal intensity of $m h[m e l]$ and $m h[s i m]$ as well as $m h[m e l], Z h r$ and $m h[s i m], Z h r$ to the mean intensity signal of the $m h[m e l]$ and $m h[m e l], Z h r$ controls, respectively.

\section{ACKNOWLEDGEMENTS}

We thank Isabella Farkas and Courtney Christopher for technical assistance. We also thank the Levine Lab, M. Patel, N. Phadnis, A. Das, and D. Dudka for feedback on the manuscript and the was supported by a Life Sciences Research Foundation fellowship to C.L.B. and National Institutes of Health (NIH) NIGMS grant R35GM124684 to M.T.L. 
Figure 1. MH evolves adaptively to preserve female fertility. (A) Counts of synonymous and nonsynonymous polymorphic and fixed sites within and between $D$. melanogaster and $D$. simulans; $X^{2}$ test, $p=0.04$. (B) Swap strategy: the $D$. melanogaster (" $D$. mel', blue) or $D$. simulans ("D. sim," yellow) $m h$ coding sequence, codon-optimized for $D$. melanogaster and 3xFLAG-tagged, replaced the native $m h$ gene on the X chromosome. (C) Total offspring from $m h[m e l]$ or $m h[s i m]$ females crossed to wildtype $\left(w^{1118}\right)$ males. (D) Ovary size estimates from $\mathrm{mh}[\mathrm{mel}]$ and $\mathrm{mh}[\mathrm{sim}]$ females. $\left(t\right.$-test: “*” $=p<0.05, "{ }^{\prime * * * ”}=p<0.001$, scale bar $\left.=100 \mu \mathrm{m}\right)$

Figure 2. MH[sim] is toxic to oogenesis. (A) Diagram of a Drosophila ovary (above) and a single ovariole (below) with the germline stem cells in the germarium on the left side and the mature eggs on the right side. The dashed box shows the developmental stages represented in images in (B), (C) and (D) (Created using BioRender.com). (B) Anti-FLAG staining to visualize $\mathrm{MH}[\mathrm{mel}]$ and $\mathrm{MH}[\mathrm{sim}]$ localization, under the native promoter. Merged images of single nuclei show no MH foci on the DNA (dashed boxes). (C) Anti-FLAG staining to visualize MH[mel] and $\mathrm{MH}[\operatorname{sim}]$ localization upon overexpression under the UAS-GAL4 system (nanos-Gal4:VP16 driver) (left). Progeny counts of the nanos-GAL4 driven UASp-mh[mel] or UASp$\mathrm{mh}$ [sim] females (right). Note that wildtype $m h$ is present in these genotypes. (D) Incidence of cell death captured by the fraction of ovarioles with condensed nuclei (arrow heads) in $m h[\mathrm{mel}]$ and $m h$ [sim] ovaries. $(t$-test, "***” $=p<0.001$, scale bar $=25 \mu \mathrm{m})$

Figure 3. MH[sim] triggers DNA damage in the ovary. (A) $\mathrm{yH} 2 \mathrm{Av}$ signal in $m h[m e l]$ and $m h$ [sim] ovaries (left) and quantification of normalized fluorescent signal intensity (right). Note that the expected $\mathrm{\gamma H} 2 \mathrm{Av}$-positive cells in the germarium in $\mathrm{mh}[\mathrm{mel}]$ are absent under the imaging parameters used but are indeed present, see Figure S2. (B) Ovary size of

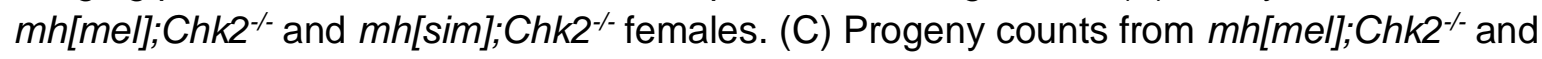
0.05 , scale bar $=25 \mu \mathrm{m}$ )

\section{Figure 4. The 359 satellite deletion rescues $\mathrm{mh}$ [sim] genome integrity and fertility. (A)} $\mathrm{YH} 2 \mathrm{Av}$ signal in $m h[m e l], Z h r$ (Zhr is the 359-deletion locus) and $m h$ [sim],Zhr ovaries (left) and quantification of normalized fluorescent signal intensity (right) (B) Ovary size of $m h[m e l], Z h r$ and $m h[s i m], Z h r$ females. (C) Progeny counts from $m h[m e l], Z h r$ and $m h$ [sim],Zhr females crossed to wildtype $\left(w^{1118}\right)$ males. ( $t$-test, "n.s." $p>0.05$, scale bar $\left.=25 \mu \mathrm{m}\right)$ (D) Cartoon summary showing outcome of adaptive evolution of $m h$ along the $D$. melanogaster (blue square) and $D$. simulans (yellow square) lineages and the expansion of 359 along the $D$. melanogaster lineage (blue semicircles). In $D$. simulans, the $X$ pericentromere lacks the $11 \mathrm{Mb} 359$ array and instead harbors other repeats, possibly repeats that $\mathrm{MH}[\mathrm{sim}]$ specifically packages (yellow triangles). Engineering an evolutionary mismatch between the $D$. melanogaster 359 locus and the $D$. simulans version of $\mathrm{MH}$ resulted in compromised genome integrity. (E) Model for $\mathrm{MH}$ evolution tracking the 359 satellite evolution. 
Figure S1. MH[sim] is expressed at comparable levels to $\mathrm{MH}[\mathrm{mel}]$ and does not phenocopy $\boldsymbol{m h}$ null. (A) Western Blot of $\mathrm{mh}[\mathrm{mel}]$ and $\mathrm{mh}$ [sim] ovaries probed with anti-FLAG or anti-tubulin. (B) Ovary size of $m h[1]$ homozygote and heterozygote females. (C) Images of embryos from crosses between EGFP-cid fathers and $\mathrm{mh}[\mathrm{mel}]$ or $\mathrm{mh}$ [sim] mothers stained with anti-GFP to identify diploid embryos.

Figure S2. $\mathbf{y}$ 2Av staining in $\boldsymbol{m h}[\mathrm{mel}]$ germarium. Diagram of a Drosophila ovariole (above) showing the germarium where meiotic recombination occurs. Germarium of an $\mathrm{mh}$ [mel] female (below) showing programmed double stranded breaks (arrowheads) occurring in "region 2A" of the germarium detected under higher laser power than used for images displayed in Figure $3 A$. These double stranded breaks are repaired via meiotic recombination pathways.

Figure S3. Deleting the X-linked 359 array rescues $m h$ [sim] genome integrity. (A) A 10cycle PCR distinguishes between wildtype 359 copy number and the 359-deletion on the $X$ chromosome (Zhr). (B) Model of $\mathrm{MH}$ [sim] toxicity. In an $m h$ [mel] ovary, transient DNA crosslinks accumulate at 359 but are resolved by other factors such as GCNA [37], which shares a Spartan-like domain with $\mathrm{MH}$. In an $\mathrm{mh}$ [sim] ovary, $\mathrm{MH}$ [sim] localizes to 359 and traps crosslinked proteins, compromising germline genome integrity. In a Zhr background, $\mathrm{MH}$ [sim] has no target to poison because the $11 \mathrm{Mb}$ array of 359 is missing. Consequently, genome integrity is restored. 


\section{LITERATURE CITED}

417 1. Thakur, J., Packiaraj, J., and Henikoff, S. (2021). Sequence, Chromatin and Evolution of Satellite DNA. Int J Mol Sci 22.

\section{Rosic, S., Kohler, F., and Erhardt,}

2. Cechova, M., Harris, R.S., Tomaszkiewicz, M., Arbeithuber, B., Chiaromonte, F., and

Makova, K.D. (2019). High satellite repeat turnover in great apes studied with short- and

3. Sproul, J.S., Khost, D.E., Eickbush, D.G., Negm, S., Wei, X., Wong, I., and Larracuente, A.M. (2020). Dynamic Evolution of Euchromatic Satellites on the X Chromosome in

Drosophila melanogaster and the simulans Clade. Mol Biol Evol 37, 2241-2256.

4. Jagannathan, M., Warsinger-Pepe, N., Watase, G.J., and Yamashita, Y.M. (2017). Comparative Analysis of Satellite DNA in the Drosophila melanogaster Species Complex. G3 (Bethesda) 7, 693-704.

5. Jagannathan, M., Cummings, R., and Yamashita, Y.M. (2018). A conserved function for pericentromeric satellite DNA. Elife 7.

6. Joshi, S.S., and Meller, V.H. (2017). Satellite Repeats Identify X Chromatin for Dosage

Compensation in Drosophila melanogaster Males. Curr Biol 27, 1393-1402 e1392.

7. Rudd, M.K., and Willard, H.F. (2004). Analysis of the centromeric regions of the human genome assembly. Trends Genet 20, 529-533.

8. Round, E.K., Flowers, S.K., and Richards, E.J. (1997). Arabidopsis thaliana centromere regions: genetic map positions and repetitive DNA structure. Genome Res 7, 1045-1053.

9. Kipling, D., Ackford, H.E., Taylor, B.A., and Cooke, H.J. (1991). Mouse minor satellite DNA genetically maps to the centromere and is physically linked to the proximal telomere. Genomics 11, 235-241.

10. Rosic, S., Kohler, F., and Erhardt, S. (2014). Repetitive centromeric satellite RNA is

11. Henikoff, S., Ahmad, K., and Malik, H.S. (2001). The centromere paradox: stable

12. Tang, X., Cao, J., Zhang, L., Huang, Y., Zhang, Q., and Rong, Y.S. (2017). Maternal Haploid, a Metalloprotease Enriched at the Largest Satellite Repeat and Essential for Genome Integrity in Drosophila Embryos. Genetics 206, 1829-1839.

13. Ferree, P.M., and Prasad, S. (2012). How can satellite DNA divergence cause reproductive isolation? Let us count the chromosomal ways. Genet Res Int 2012, 430136.

14. Jagannathan, M., and Yamashita, Y.M. (2021). Defective satellite DNA clustering into chromocenters underlies hybrid incompatibility in $<$ em $>$ Drosophila</em $>$. bioRxiv, 2021.2004.2016.440167.

15. Bayes, J.J., and Malik, H.S. (2009). Altered heterochromatin binding by a hybrid sterility protein in Drosophila sibling species. Science 326, 1538-1541.

16. Kumon, T., Ma, J., Stefanik, D., Nordgren, E.C., Akins, R.B., Kim, J., Levine, M.T., and Lampson, M.A. (2020). Centromere drive and suppression by parallel pathways for recruiting microtubule destabilizers. bioRxiv, 2020.2011.2026.400515. 
17. Maheshwari, S., Tan, E.H., West, A., Franklin, F.C.H., Comai, L., and Chan, S.W.L. (2015). Naturally occurring differences in CENH3 affect chromosome segregation in zygotic mitosis of hybrids. PLoS Genet 11, e1004970.

18. Ferree, P.M., and Barbash, D.A. (2009). Species-specific heterochromatin prevents mitotic chromosome segregation to cause hybrid lethality in Drosophila. PLoS Biol 7, e1000234.

19. Gibeaux, R., Acker, R., Kitaoka, M., Georgiou, G., van Kruijsbergen, I., Ford, B., Marcotte, E.M., Nomura, D.K., Kwon, T., Veenstra, G.J.C., et al. (2018). Paternal chromosome loss and metabolic crisis contribute to hybrid inviability in Xenopus. Nature 553, 337-341.

20. Lohe, A.R., Hilliker, A.J., and Roberts, P.A. (1993). Mapping simple repeated DNA sequences in heterochromatin of Drosophila melanogaster. Genetics 134, 1149-1174.

21. Brutlag, D.L. (1980). Molecular arrangement and evolution of heterochromatic DNA. Annu Rev Genet 14, 121-144.

22. de Lima, L.G., Hanlon, S.L., and Gerton, J.L. (2020). Origins and Evolutionary Patterns of the 1.688 Satellite DNA Family in Drosophila Phylogeny. G3 (Bethesda) 10, 41294146.

23. Abad, J.P., Agudo, M., Molina, I., Losada, A., Ripoll, P., and Villasante, A. (2000). Pericentromeric regions containing 1.688 satellite DNA sequences show antikinetochore antibody staining in prometaphase chromosomes of Drosophila melanogaster. Mol Gen Genet 264, 371-377.

24. Losada, A., and Villasante, A. (1996). Autosomal location of a new subtype of 1.688 satellite DNA of Drosophila melanogaster. Chromosome Res 4, 372-383.

25. Delabaere, L., Orsi, G.A., Sapey-Triomphe, L., Horard, B., Couble, P., and Loppin, B. (2014). The Spartan ortholog maternal haploid is required for paternal chromosome integrity in the Drosophila zygote. Curr Biol 24, 2281-2287.

26. McDonald, J.H., and Kreitman, M. (1991). Adaptive protein evolution at the Adh locus in Drosophila. Nature 351, 652-654.

27. Garrigan, D., Kingan, S.B., Geneva, A.J., Andolfatto, P., Clark, A.G., Thornton, K.R., and Presgraves, D.C. (2012). Genome sequencing reveals complex speciation in the Drosophila simulans clade. Genome Res 22, 1499-1511.

28. Kerr, J.F., Wyllie, A.H., and Currie, A.R. (1972). Apoptosis: a basic biological phenomenon with wide-ranging implications in tissue kinetics. Br J Cancer 26, 239-257.

29. McCall, K. (2004). Eggs over easy: cell death in the Drosophila ovary. Dev Biol 274, 314.

30. Roos, W.P., Thomas, A.D., and Kaina, B. (2016). DNA damage and the balance between survival and death in cancer biology. Nat Rev Cancer 16, 20-33.

31. Bakhrat, A., Pritchett, T., Peretz, G., McCall, K., and Abdu, U. (2010). Drosophila Chk2 and p53 proteins induce stage-specific cell death independently during oogenesis. Apoptosis 15, 1425-1434.

32. Brodsky, M.H., Weinert, B.T., Tsang, G., Rong, Y.S., McGinnis, N.M., Golic, K.G., Rio, D.C., and Rubin, G.M. (2004). Drosophila melanogaster MNK/Chk2 and p53 regulate multiple DNA repair and apoptotic pathways following DNA damage. Mol Cell Biol 24, 1219-1231. 
501

33. Sawamura, K., Yamamoto, M.T., and Watanabe, T.K. (1993). Hybrid lethal systems in the Drosophila melanogaster species complex. II. The Zygotic hybrid rescue (Zhr) gene of D. melanogaster. Genetics 133, 307-313.

34. Morocz, M., Zsigmond, E., Toth, R., Enyedi, M.Z., Pinter, L., and Haracska, L. (2017). DNA-dependent protease activity of human Spartan facilitates replication of DNA-protein crosslink-containing DNA. Nucleic Acids Res 45, 3172-3188.

35. Stingele, J., Bellelli, R., Alte, F., Hewitt, G., Sarek, G., Maslen, S.L., Tsutakawa, S.E., Borg, A., Kjaer, S., Tainer, J.A., et al. (2016). Mechanism and Regulation of DNA-Protein Crosslink Repair by the DNA-Dependent Metalloprotease SPRTN. Mol Cell 64, 688-703.

36. Vaz, B., Popovic, M., Newman, J.A., Fielden, J., Aitkenhead, H., Halder, S., Singh, A.N., Vendrell, I., Fischer, R., Torrecilla, I., et al. (2016). Metalloprotease SPRTN/DVC1 Orchestrates Replication-Coupled DNA-Protein Crosslink Repair. Mol Cell 64, 704-719.

37. Bhargava, V., Goldstein, C.D., Russell, L., Xu, L., Ahmed, M., Li, W., Casey, A., Servage, K., Kollipara, R., Picciarelli, Z., et al. (2020). GCNA Preserves Genome Integrity and Fertility Across Species. Dev Cell 52, 38-52 e10.

38. Chmátal, L., Gabriel, S.I., Mitsainas, G.P., Martínez-Vargas, J., Ventura, J., Searle, J.B., Schultz, R.M., and Lampson, M.A. (2014). Centromere strength provides the cell biological basis for meiotic drive and karyotype evolution in mice. Current biology: $\mathrm{CB}$ 24, 2295-2300.

39. Iwata-Otsubo, A., Dawicki-McKenna, J.M., Akera, T., Falk, S.J., Chmátal, L., Yang, K., Sullivan, B.A., Schultz, R.M., Lampson, M.A., and Black, B.E. (2017). Expanded Satellite Repeats Amplify a Discrete CENP-A Nucleosome Assembly Site on Chromosomes that Drive in Female Meiosis. Current biology: CB 27, 2365-2373.e2368.

40. Carracedo, M.C., Asenjo, A., and Casares, P. (2000). Location of Shfr, a new gene that rescues hybrid female viability in crosses between Drosophila simulans females and D. melanogaster males. Heredity (Edinb) 84 ( Pt 6), 630-638.

41. Gerard, P.R., and Presgraves, D.C. (2012). Abundant genetic variability in Drosophila simulans for hybrid female lethality in interspecific crosses to Drosophila melanogaster. Genet Res (Camb) 94, 1-7.

42. Orr, H.A. (1996). The unexpected recovery of hybrids in a Drosophila species cross: a genetic analysis. Genet Res 67, 11-18.

43. Sawamura, K., Taira, T., and Watanabe, T.K. (1993). Hybrid lethal systems in the Drosophila melanogaster species complex. I. The maternal hybrid rescue $(\mathrm{mhr})$ gene of Drosophila simulans. Genetics 133, 299-305.

44. Sawamura, K., and Yamamoto, M.T. (1993). Cytogenetical localization of Zygotic hybrid rescue (Zhr), a Drosophila melanogaster gene that rescues interspecific hybrids from embryonic lethality. Mol Gen Genet 239, 441-449.

45. Pool, J.E., Corbett-Detig, R.B., Sugino, R.P., Stevens, K.A., Cardeno, C.M., Crepeau, M.W., Duchen, P., Emerson, J.J., Saelao, P., Begun, D.J., et al. (2012). Population Genomics of sub-saharan Drosophila melanogaster: African diversity and non-African admixture. PLoS Genet 8, e1003080.

46. Rogers, R.L., Cridland, J.M., Shao, L., Hu, T.T., Andolfatto, P., and Thornton, K.R. (2014). Landscape of standing variation for tandem duplications in Drosophila yakuba and Drosophila simulans. Mol Biol Evol 31, 1750-1766. 
545 47. Venken, K.J., He, Y., Hoskins, R.A., and Bellen, H.J. (2006). P[acman]: a BAC transgenic platform for targeted insertion of large DNA fragments in D. melanogaster. Science 314, 1747-1751.

548 48. Schindelin, J., Arganda-Carreras, I., Frise, E., Kaynig, V., Longair, M., Pietzsch, T.,

549 Preibisch, S., Rueden, C., Saalfeld, S., Schmid, B., et al. (2012). Fiji: an open-source platform for biological-image analysis. Nat Methods 9, 676-682.

49. McKim, K.S., Joyce, E.F., and Jang, J.K. (2009). Cytological analysis of meiosis in fixed

50. Schuh, M., Lehner, C.F., and Heidmann, S. (2007). Incorporation of Drosophila Drosophila ovaries. Methods Mol Biol 558, 197-216.

CID/CENP-A and CENP-C into centromeres during early embryonic anaphase. Curr Biol 17, 237-243.

51. Levine, M.T., Vander Wende, H.M., and Malik, H.S. (2015). Mitotic fidelity requires transgenerational action of a testis-restricted HP1. Elife 4, e07378. 
bioRxiv preprint doi: https://doi.org/10.1101/2021.08.13.455988; this version posted August 13, 2021. The copyright holder for this preprint (which was not certified by peer review) is the author/funder, who has granted bioRxiv a license to display the preprint in perpetuity. It is made available under aCC-BY 4.0 International license.

C

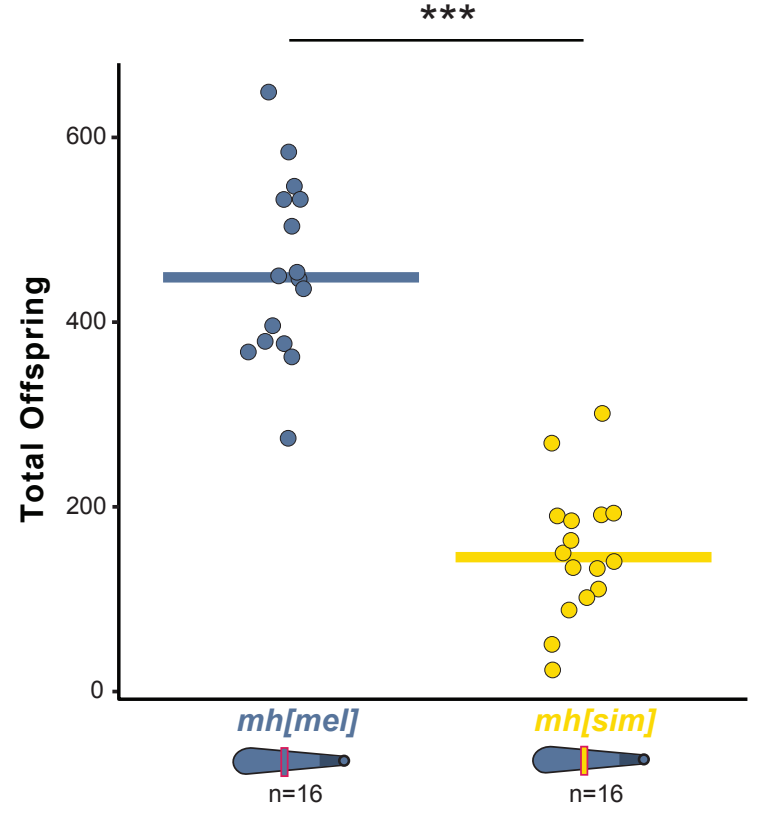

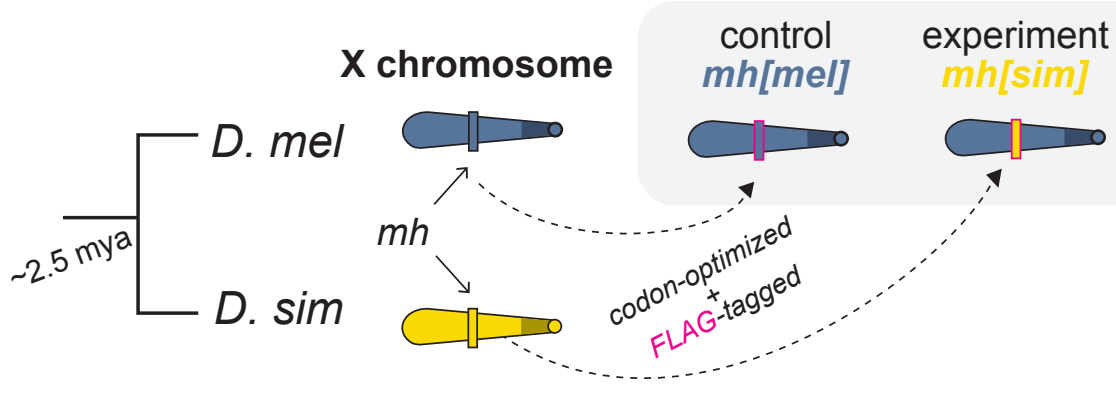

D

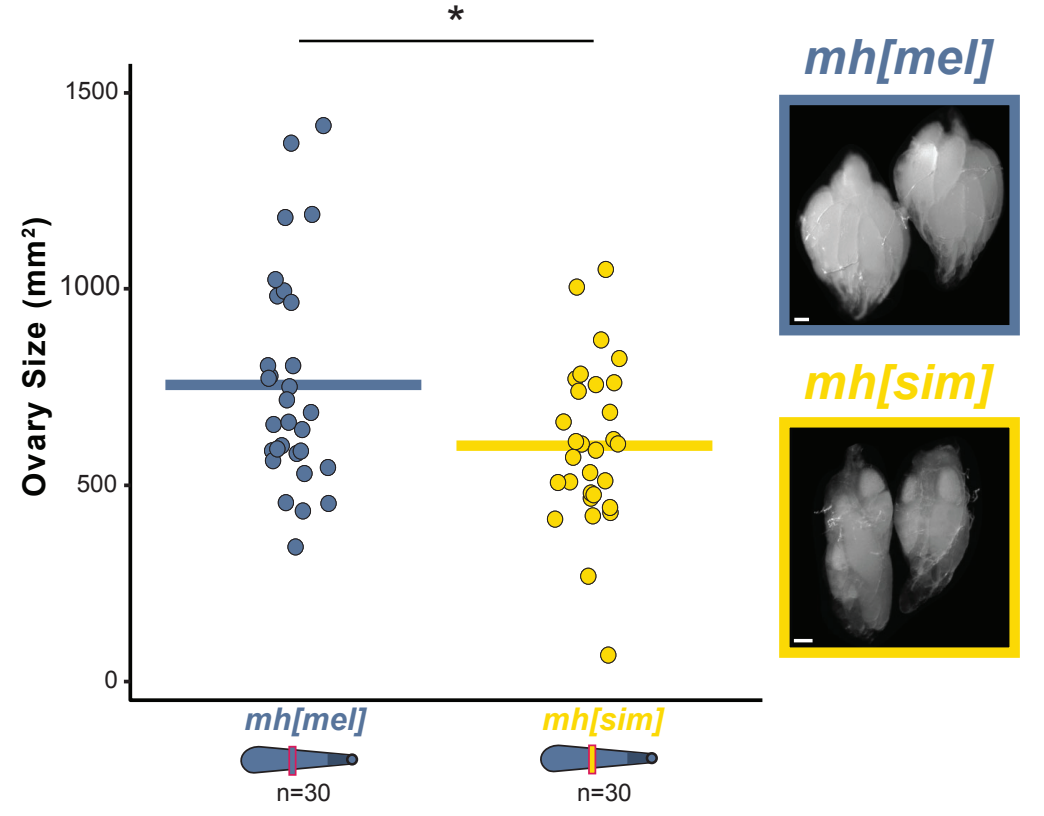


bioRxiv preprint doi: https://doi.org/10.1101/2021.08.13.455988; this version posted August 13, 2021. The copyright holder for this preprint (which was not certified by peer review) is the author/funder, who has granted bioRxiv a license to display the preprint in perpetuity. It is made available under aCC-BY 4.0 International license.

A
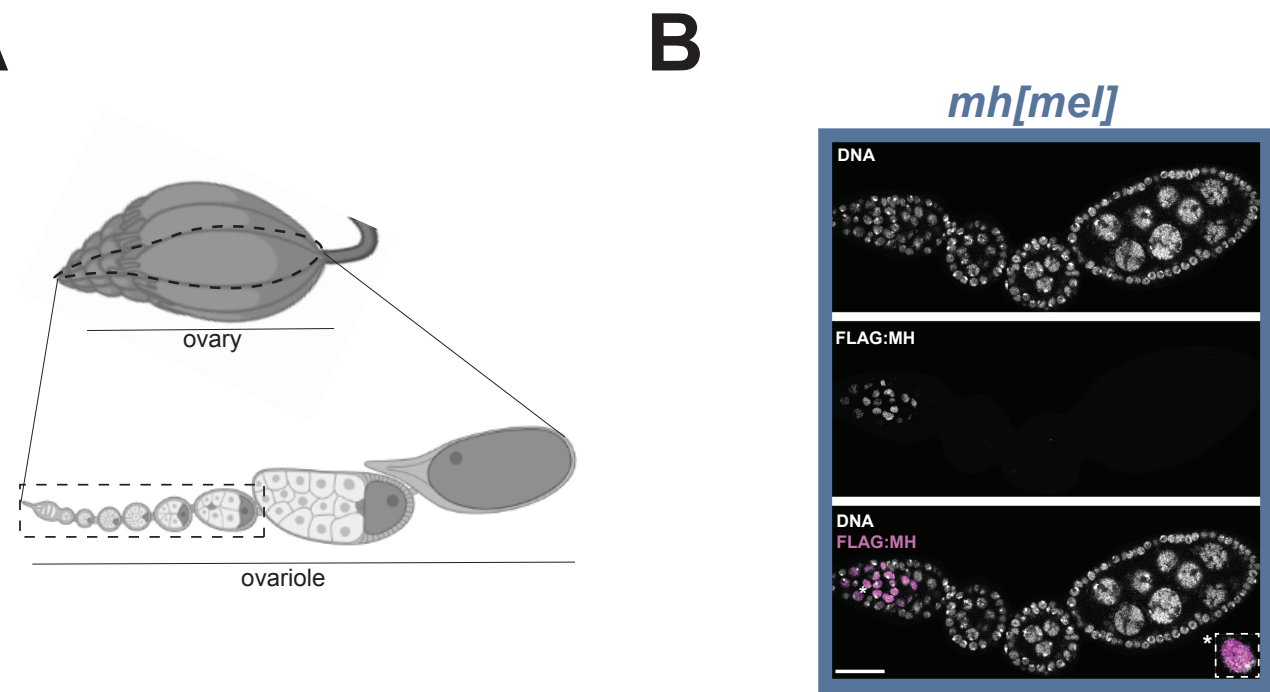

$m h[\operatorname{sim}]$

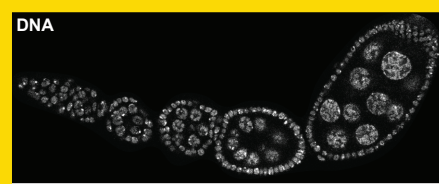

\section{FLAG:MH}

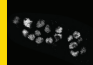

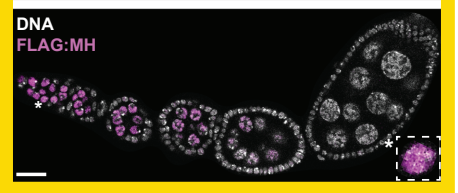

nanos-Gal4 > UASp-mh[mel]
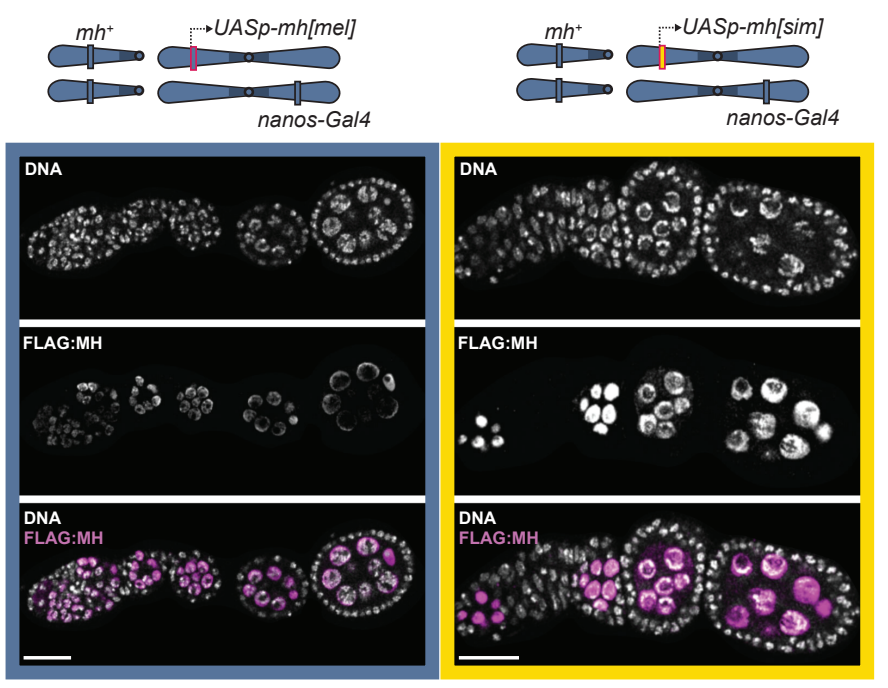

nanos-Gal4 > UASp- $m h[\operatorname{sim}]$
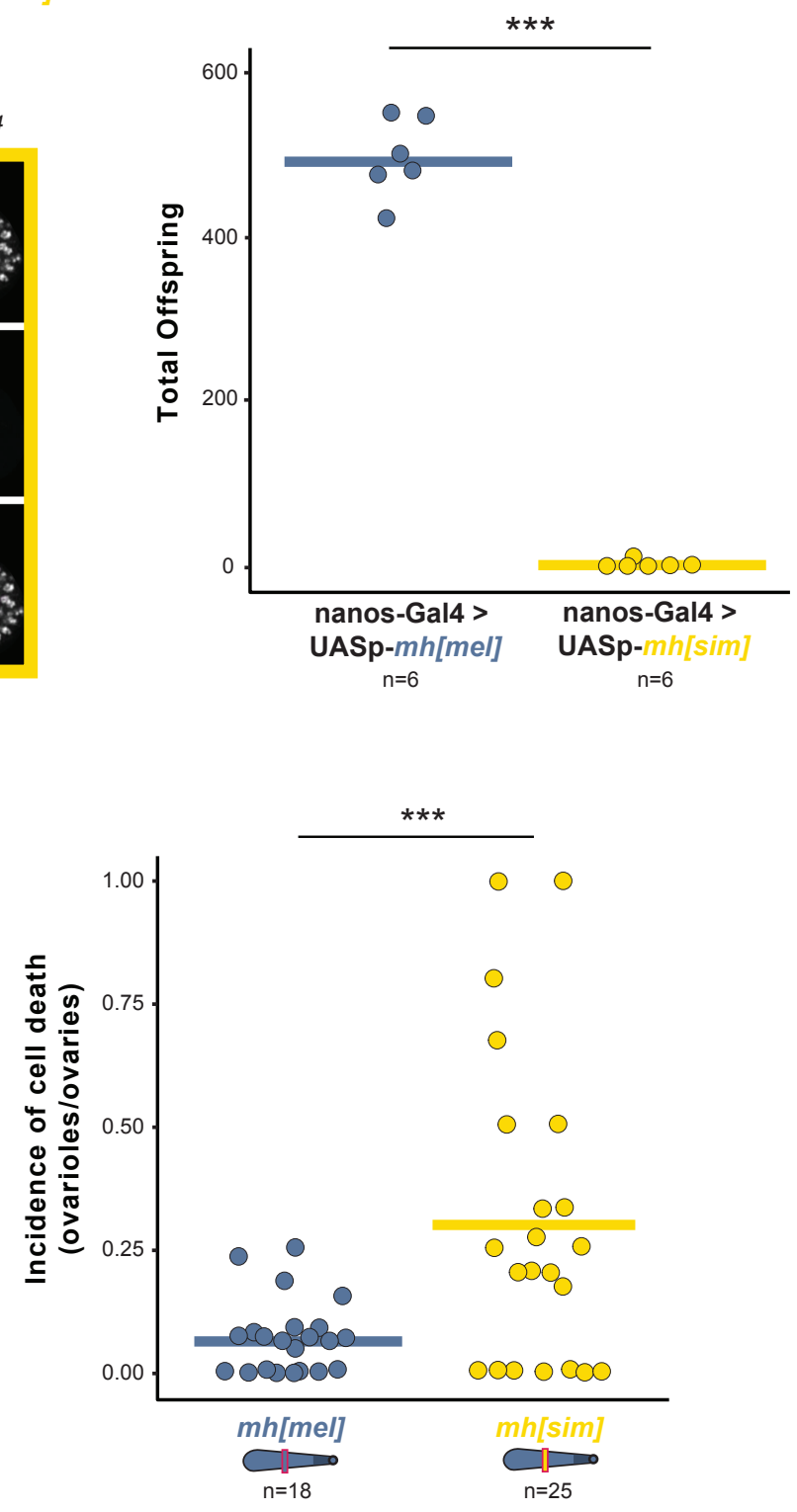

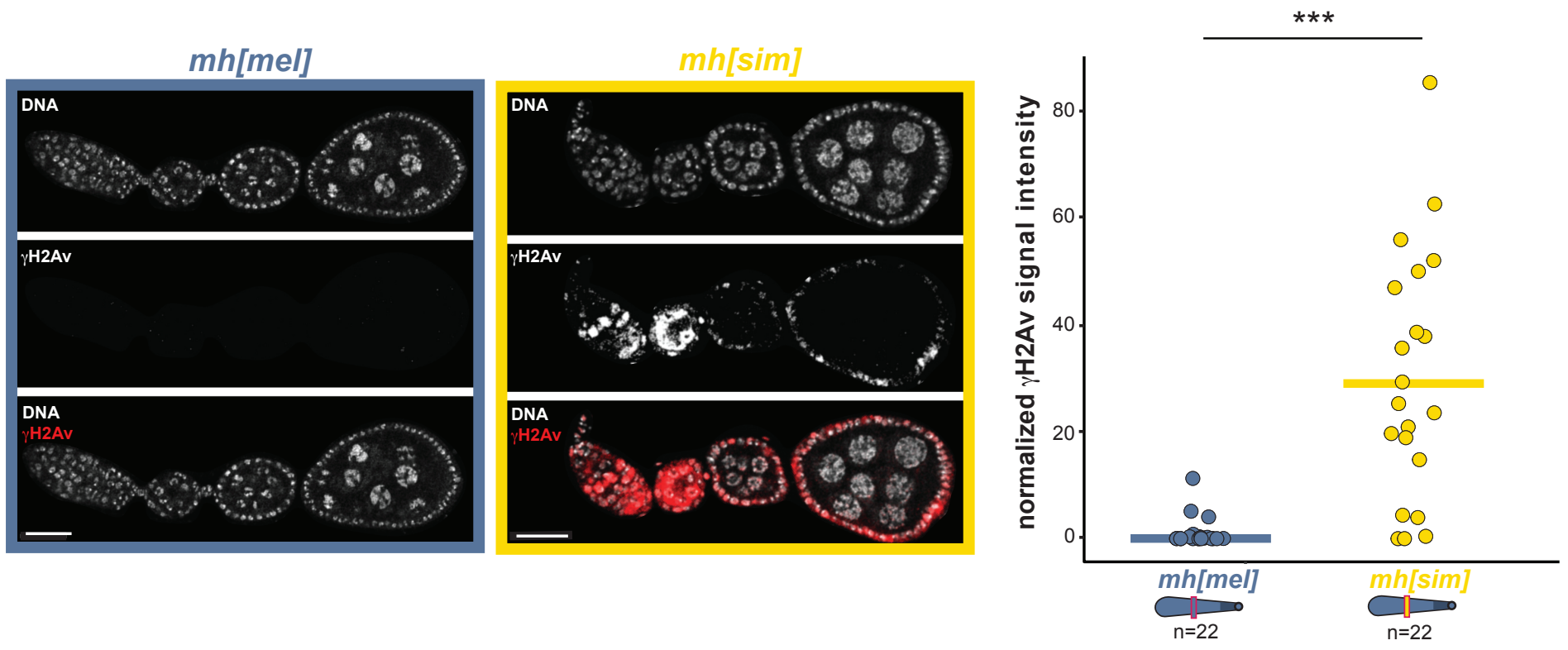

B

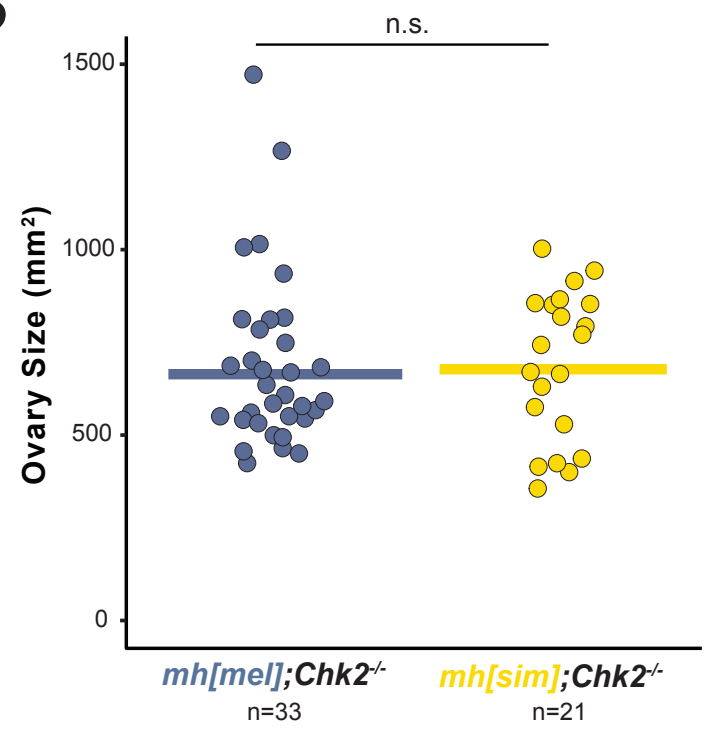

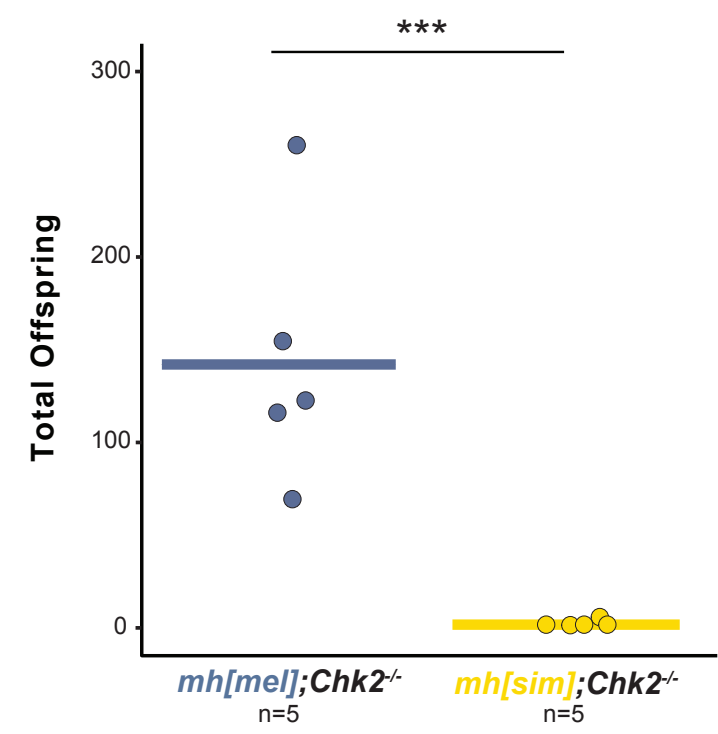


bioRxiv preprint doi: https://doi.org/10.1101/2021.08.13.455988; this version posted August 13, 2021. The copyright holder for this preprint (which was not certified by peer review) is the author/funder, who has granted bioRxiv a license to display the preprint in perpetuity. It is made $\Delta$ available under aCC-BY 4.0 International license.
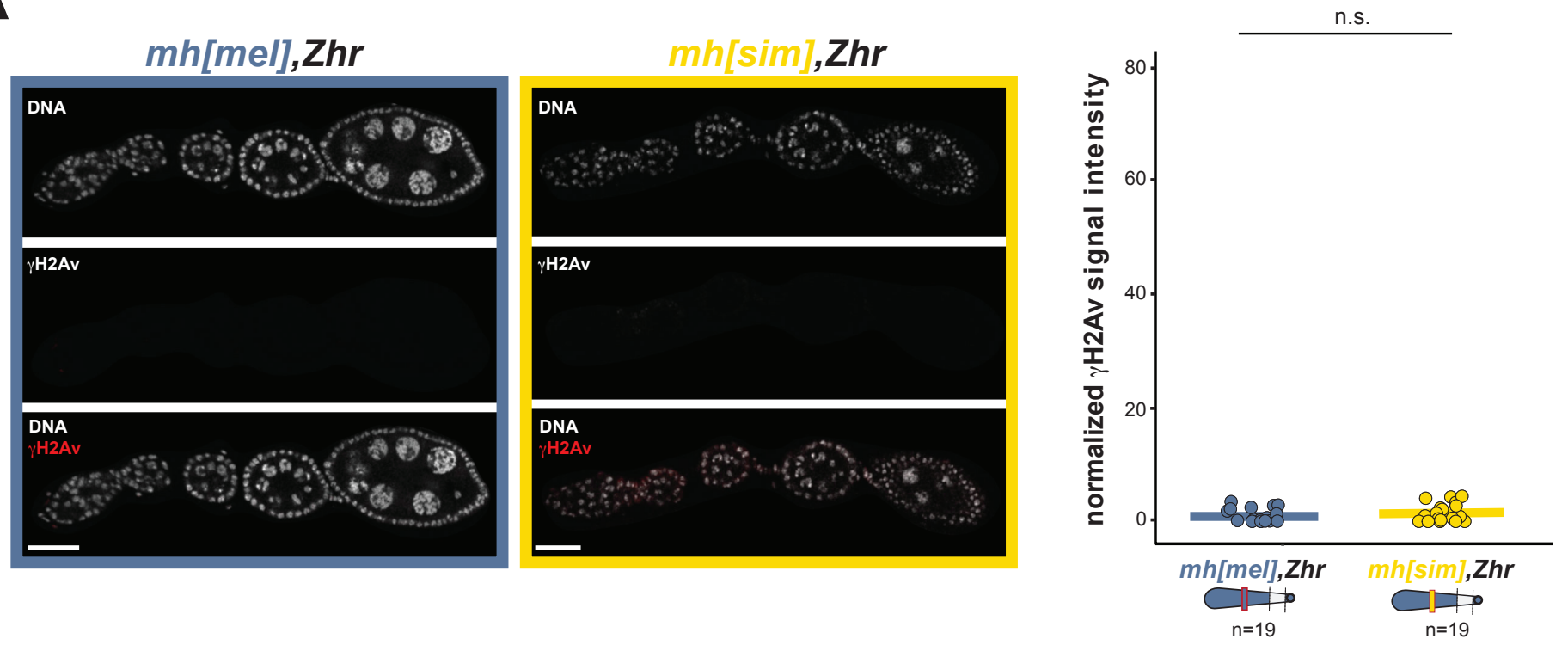

B

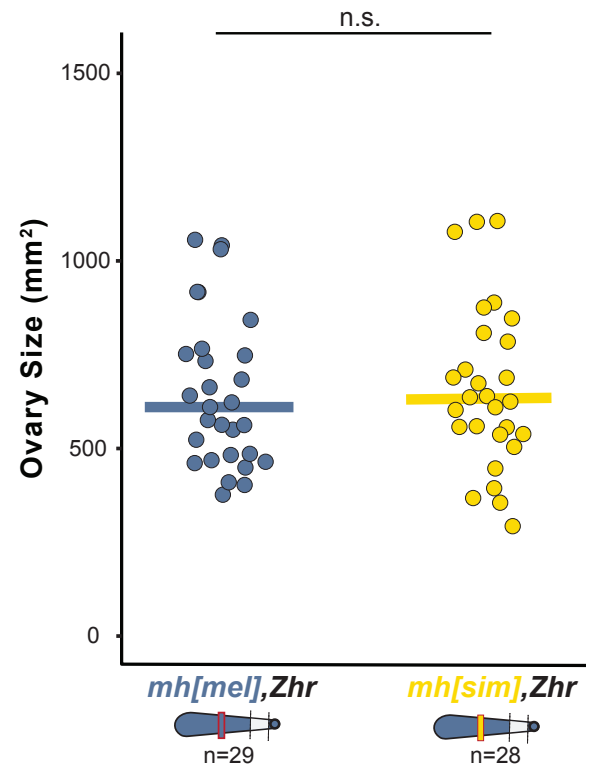

D

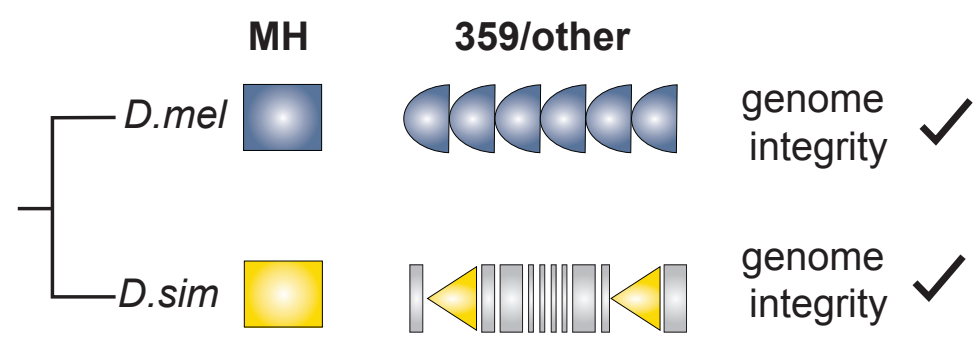

evolutionary mismatch genome

integrity

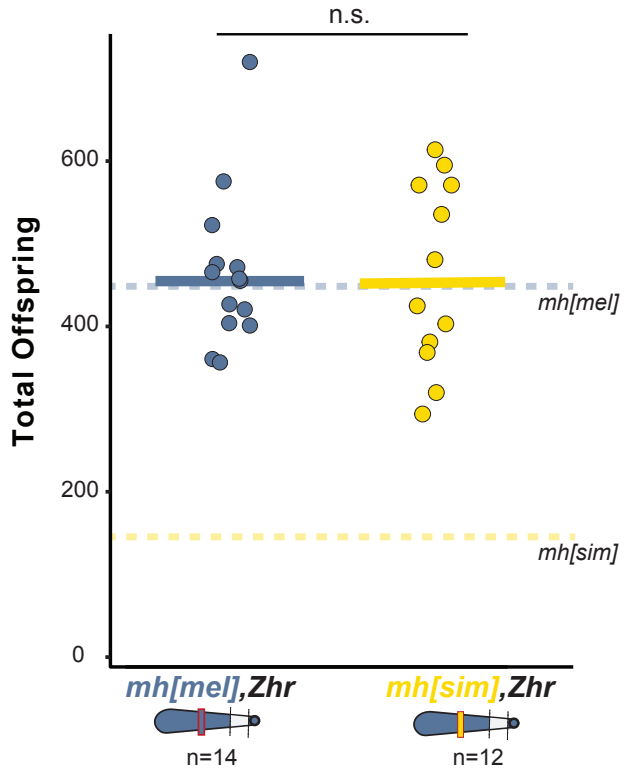

E

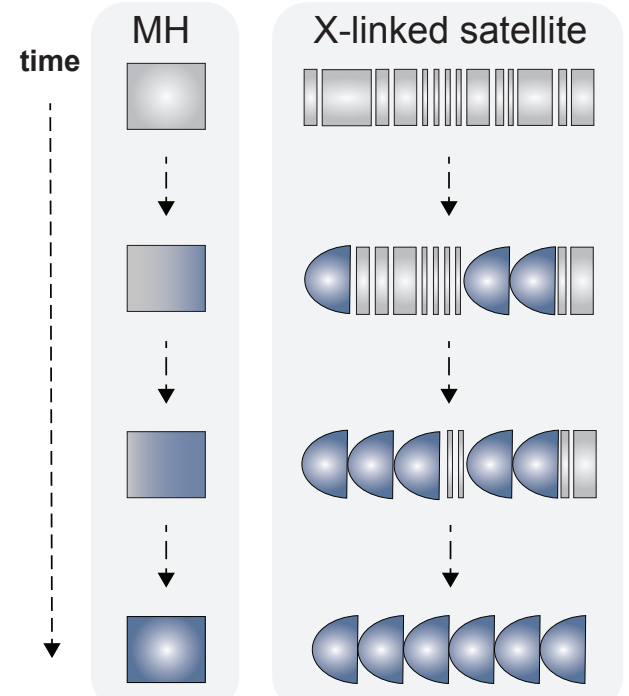




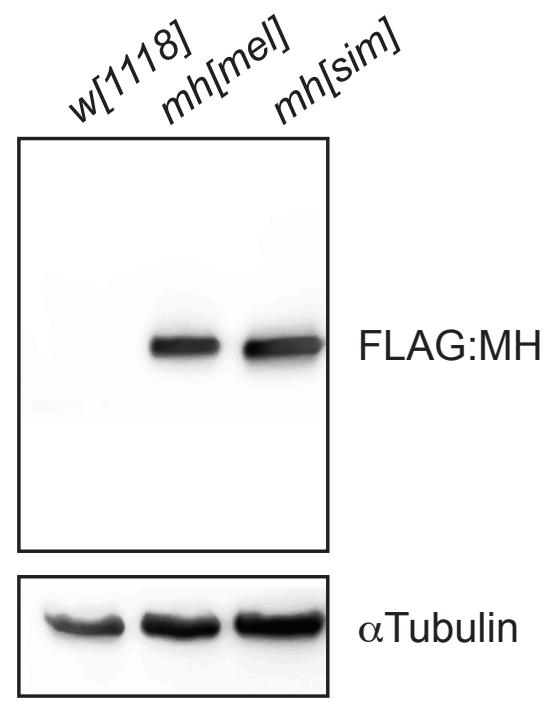

mother: $m h[m e l]$

father: eGFP-cid

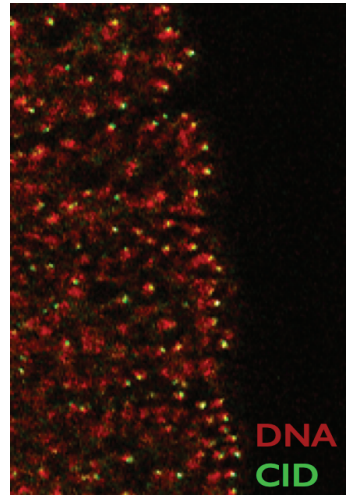

93\% eGFP-detected

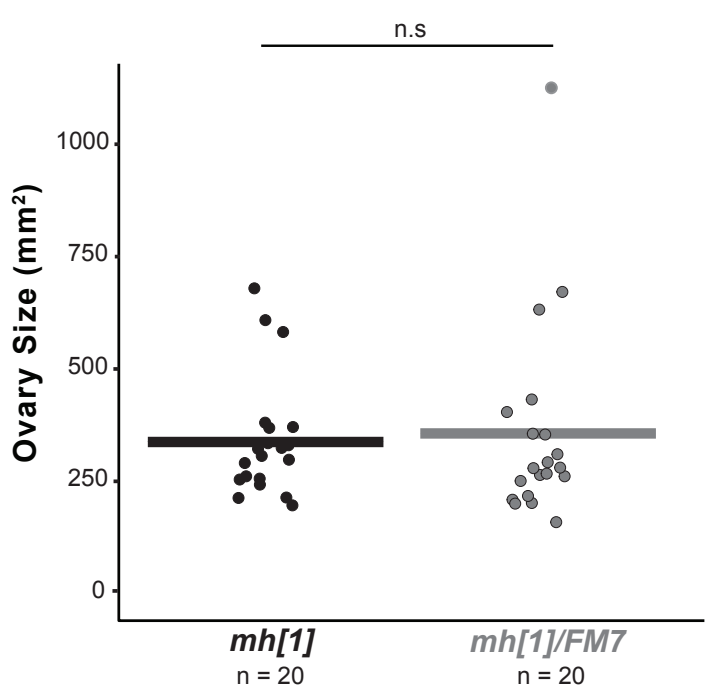

B

$\mathrm{n}=20$

$\mathrm{n}=20$ mother: $m h[\mathrm{sim}]$

father: eGFP-cid

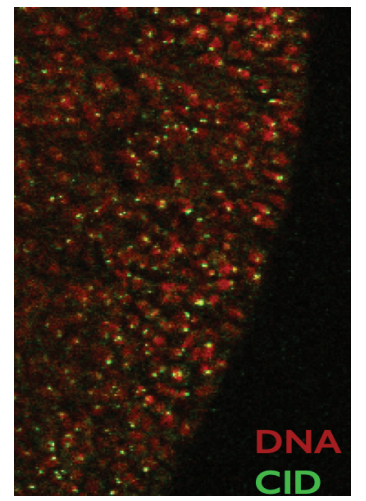

98\% eGFP-detected 
bioRxiv preprint doi: https://doi.org/10.1101/2021.08.13.455988; this version posted August 13, 2021. The copyright holder for this preprint (which was not certified by peer review) is the author/funder, who has granted bioRxiv a license to display the preprint in perpetuity. It is made available under aCC-BY 4.0 International license.

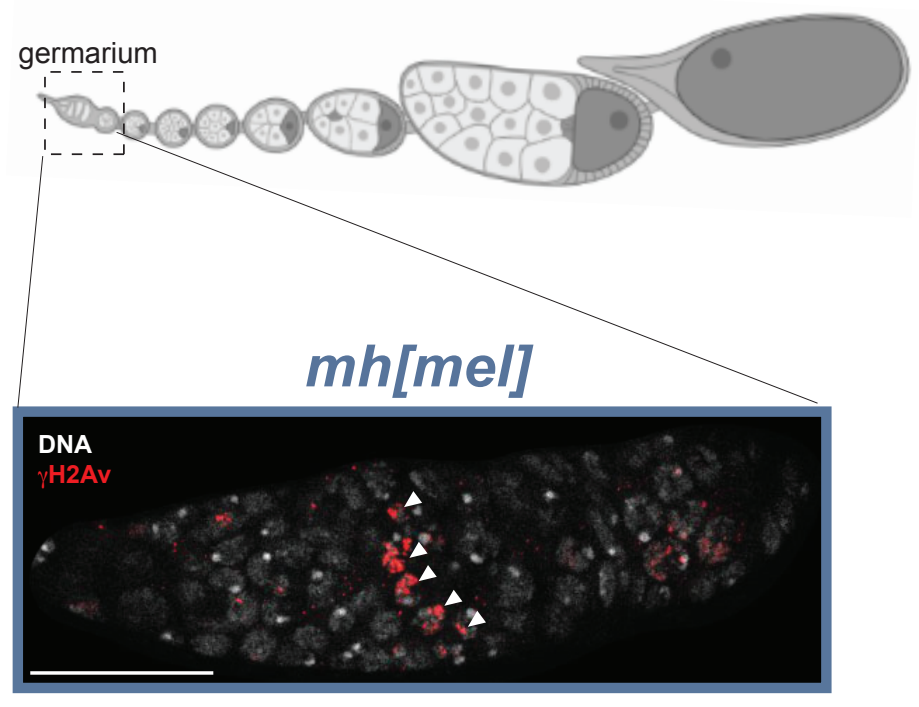


A

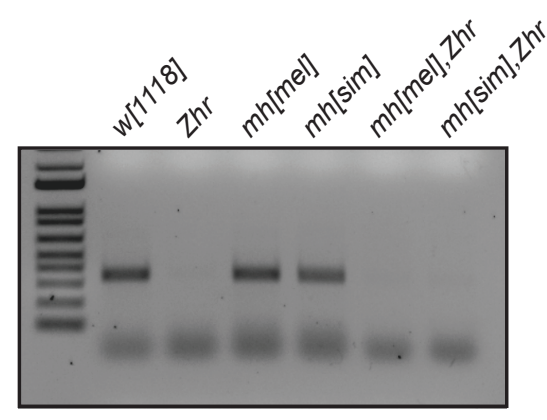

B
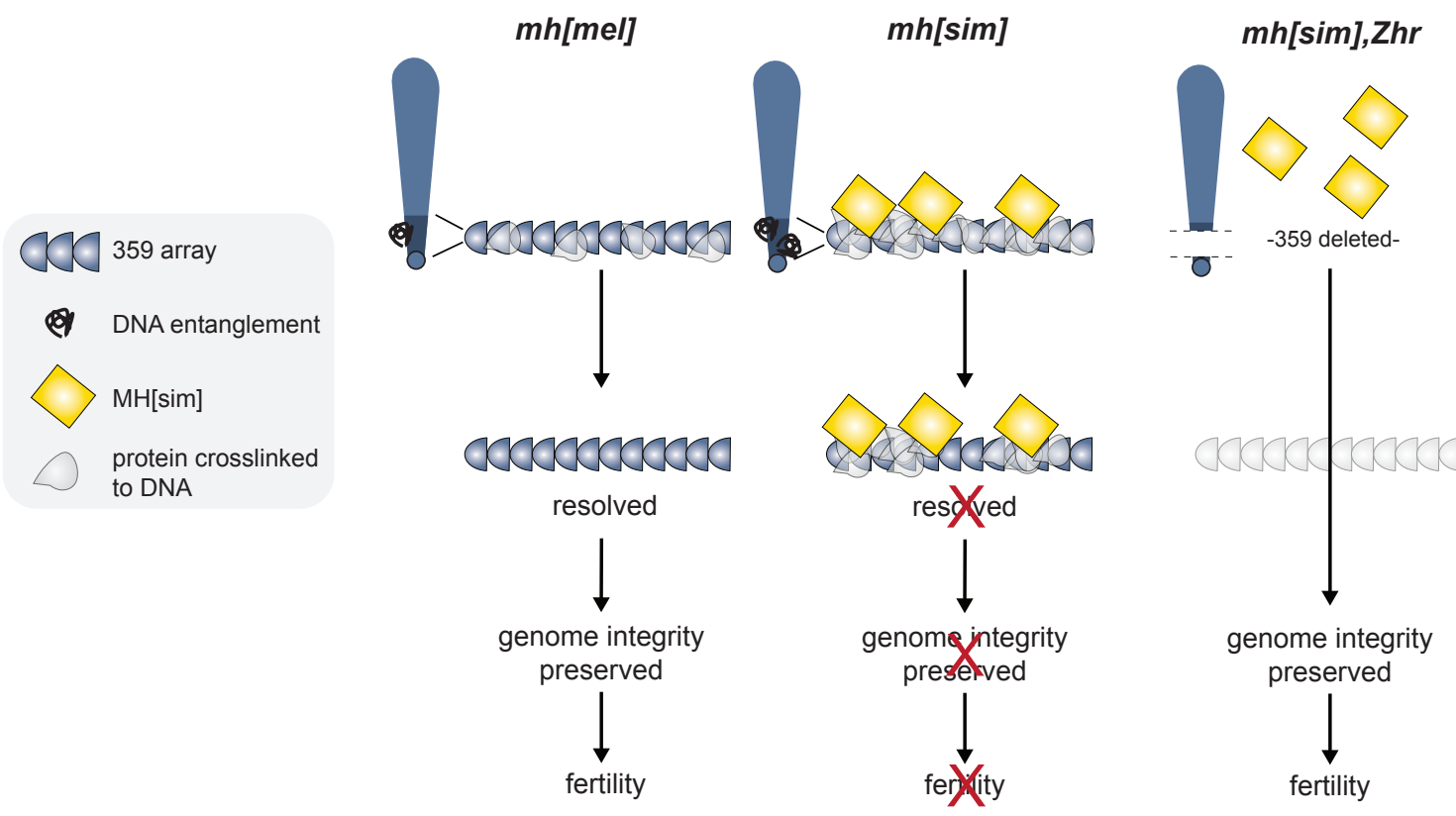